\title{
A ostensão penal: notas críticas sobre a vertigem da punição
}

\section{The criminal ostension: critical notes on the vertigo of punishment}

Augusto Jobim do Amaral ${ }^{*}$

\section{Resumo}

Neste artigo, examina-se o esplendor da cultura punitiva contemporânea, em especial, analisam-se as demandas punitivas e a formação disponível na sua profunda aclamação populista. Por fim, após apresentar a impotência coletiva em tornar os direitos humanos uma medida de ação política concreta para além da estéril aposta penal, percorre-se os influxos criminalizadores derivados de sua suposta proteção, delineando, na atual vontade de punir, a radical vertigem da ostensão penal.

Palavras-chave: Ostensão penal. Populismo punitivo. Política criminal.

\section{Abstract}

The article examines the contemporary splendor of the punitive culture, in particular analyses the punitive demands and the background available in its deep populist acclaim. Finally, after presenting the collective powerlessness to become human rights in a concrete policy beyond the criminal approach, studies the criminalizing inflows derived of the its supposed protection, outlining the current desire to punishment and the vertigo of the criminal ostension.

Keywords: Criminal ostension. Punitive populism. Criminal policy.

* Doutor em Altos Estudos Contemporâneos pela Universidade de Coimbra (Portugal). Mestre em Ciências Criminais pela Pontifícia Universidade Católica do Rio Grande do Sul (PUCRS). Especialista em Ciências Penais pela PUCRS. Especialista em Direito Penal Econômico e Europeu pela Universidade de Coimbra. Professor do Departamento de Direito Penal e Processo Penal da PUCRS. 


\section{Introdução: estilhaços de uma hipótese}

A configuração atual de uma sociedade securitária em escala mundial, sua dinâmica, metamorfose e sobreposição tem evidente importância quando se indaga acerca de questões relativas à teoria política ou mesmo aos direitos humanos. Pode-se dizer que tal sintoma invade as práticas punitivas com certo protagonismo, pelo menos no Ocidente, a partir dos anos 1970 (GARLAND, 2005). Tomada como tema central do discurso político - e este é o plano principal a ser perseguido -, a (in)segurança e sua retórica da guerra (que confunde segurança interna e externa) acabaram por atrair não somente os discursos ditos "de direita" (que lá sempre estiveram, em tempos de bonança, com seu discurso politicamente correto, mas que em tempos áridos darão as tintas do canal acessível à repressão, com xenofobia, terrorismo, crimes sexuais, drogas etc.), nem somente os dirigentes políticos, mas, sobretudo, o ativismo judicial, ganhando o espaço público como ferramenta de combate à criminalidade. Esse é o cenário sobre o qual nos debruçaremos radicalmente.

\section{A paixão de punir do populismo penal}

O populismo penal, tal como o desenhamos em hipótese, tornouse claramente um componente forte da vida democrática. Um "direito de punir" puramente repressivo, conjugado a uma democracia de opinião (efervescente), é meramente uma pequena amostra das promessas atrativas (aos eleitores) desse discurso político de emoção midiática. Sua irrupção passa a ter três elementos fundamentais: punições radicais, indiferença quanto a qualquer eficácia dessas políticas (pois vale o impacto que produz sobre a opinião publicada) e a legislação rigorosa que promete reduzir a criminalidade (SALAS, 2010).

É tempo das vítimas. O primeiro plano do combate e da punição é instalado por um imaginário vitimizadore torna fértil o terreno para a figura do vingador - precisamente, da "vítima acusadora". A diabolização do adversário é apenas a contraface da retórica do mártir e da luta contra o 
mal. A dramaturgia da cena penal vem bem a calhar nesse apartamento radical entre raiva e pena. $O$ combate do bem contra o mal numa degradada democracia dos indivíduos exaspera o retorno vitimário e a coloca naquilo que se poderia chamar de "democracia dos queixosos" (GARLAND, 2010). As cruzadas morais e populistas rompem qualquer equilíbrio que poderia haver entre a força e a forma que constitui o Estado de Direito. Algo como se, reabilitada a parte irracional do poder, houvesse o mergulho vertiginoso na violência originária que inaugura propriamente o ente estatal. Nesse ponto crítico, os papéis de vítimas e carrascos tornam-se intercambiáveis.

Para Packer (1968), o aparelho judicial pode operar como uma linha de montagem (assembly line) ao supor dois níveis para funcionar: inicialmente, o controle do crime (crime control), capitaneado pela polícia e pelo Ministério Público; e o outro, relativo ao respeito às regras de direito (due process), sob a autoridade do juiz. Na verdade, seriam mais propriamente dois modelos normativos de processos criminais que nos levariam a perceber uma antinomia no coração da justiça criminal. O primeiro é uma cadeia (literalmente) responsável, programada e preparada para transformar um suspeito em condenado, enquanto a segunda coloca-se como um obstáculo nesse percurso, que faz da proteção ao acusado um valor central.

O sistema repressivo, cada vez mais impregnado pela ideologia do "just deserts", tem sido encampado e agenciado pela justiça penal em detrimento da segunda, exatamente para dar credibilidade à instituição. Impondo-se o adágio do paradigma da eficiência, por um lado, esse valor age principalmente sobre a pequena criminalidade, com uma série de dispositivos que pragmaticamente pleiteiam a culpabilidade do réu (viabilizados no caso brasileiro, por exemplo, pela deturpação negocial dos juizados especiais criminais pelo instituto da transação penal); quanto à criminalidade "graúda", há o processo penal de exceção, e não apenas com ritos especiais, com a possibilidade permanente e geral de rompimento da regra mediante a própria previsão aberta da legislação.

A paixão por punir, alimentada pelo populismo penal, é imposta, sobretudo, pelo afeto. Quebra-se qualquer olhar compreensivo ao 
acusado à medida que a indignação coletiva relega esse olhar ao mal personificado. Mas de que forma se pode resistir à fragilização que se abate sobre as democracias por estarem envolvidas nessa ostenção penal? Como manter à distância a vertigem (alucinação) de uma demagógica comunidade de emoção? Piorando o quadro: e quando o perigo vier revelado em irracionalidade, através da melhor justificativa democrática possível - os direitos do homem -, ou seja, veiculado pela formação de uma política penal dos direitos do homem? A desnaturação de sua função de limitador do exercício punitivo é o arquétipo anunciado de sua corrosão.

Ainjunção repressiva que condena à multiplicação de incriminações reforça, além do ativismo legislativo e policial, a esfera judicial, visando a (estéril) proteção dos direitos do homem - não raro, equivale a expor a uma ilusória proteção pelo reforço do interdito. Quando se perde a referência, a infrutífera reiteração da instância legal (criminalizante) apenas denuncia a falência de sua autoridade. Lança-se mão do triunfo (ou consolo?) em matéria penal, tal qual os aliados criam na ilusória "Linha Maginot" (PIRES, 2001), como meio de resguardo ao avanço nazista. A ofensiva de um moralismo punitivo parece ter optado pela explícita escolha da expressão dos valores próprios ao risco de uma total indiferença aos direitos dos infratores.

Deparamo-nos com uma democracia jogada contra ela mesma, em que o retorno das exigências de controle, segurança e punição avançam triunfantes sobre os direitos pessoais. À medida que os direitos do homem tornam-se uma política - acrescentaríamos à expressão de Gauchet (2009) o termo penal -, percebe-se uma deriva fundamentalista conduzida pela inversão dos direitos do homem pelo excesso. Uma esquerda fora da esquerda, parafraseando o autor francês.

Os efeitos penais de uma política de repressão e criminalização, fundada na proteção de direitos fundamentais, são sinais experimentados dentro das desconcertantes faces da nova democracia, identificáveis desde o pós-guerra e com apogeu a partir dos anos 1970/1980, o que, em terras brasileiras, teve profundos desdobramentos em matéria 
constitucional. Uma democracia triunfante agora retorna a um ativismo penal em nome dos seus valores supremos, sorrateiramente implodindo as próprias bases. A afirmação de que os direitos dos homens não são uma política, agora relida, pode denunciar precisamente um inverso ameaçador que se espreita na emancipação do homem desde a esfera de seus direitos: a alienação coletiva tende a se multiplicar. Daí se defluiu o reforço do papel estatal em matéria de controle penal, além do aprofundamento do anonimato social, sem falar no agravamento do desinteresse pela coisa pública. Quer dizer, os direitos dos homens não poderão ser uma política, senão sob a condição de saberem reconhecer e superar a dinâmica alienante do individualismo veiculada naturalmente ${ }^{1}$ (GAUCHET, 2009).

A consagração dos direitos do homem como fato ideológico e político maior nos últimos tempos não deve perder de vista o contexto de que, ao serem postos como epicentro das democracias, podem se tornar a mola de sua dificuldade em ser política. Maior prova disso é a sua utilização como expressão penal criminalizadora. Dessa forma, o argumento nos auxilia a pensar com outra valência a indagação sobre o problema da cultura penal. A partir disso, somos conduzidos a aceitar a ideia de que tal plataforma - a canalização das demandas de proteção dos direitos humanos para o viés penal e toda a visão punitiva e populista de seus atores aí implicada - se apresenta como mais uma

Aqui, é importante pontuar que damos por adquirida a superação da concepção, que em algum momento permeia a tese de Gauchet (2009), de, não raro, restringir a concepção de direitos do homem à sua face individual. O alerta a certa "captura pela ideologia burguesa dos direitos do homem" já era feita na mesma época por Lefort (2011), ressaltando justamente a cegueira perante os direitos do homem, segundo certa leitura de esquerda, impotente em conceber os direitos do homem a não ser como direitos do indivíduo. Tal é a explicação para a cegueira dessa estirpe - a saber, incapaz de reconhecer neles uma aquisição irreversível do pensamento político - diante do totalitarismo, pois qualquer violação aos direitos do homem seria apenas uma violação de direitos individuais, de direitos que não seriam "políticos", sendo possível demonstrar que os erros de governo de que foram vítimas milhões de indivíduos não autorizariam pôr em causa a natureza de um Estado, já que distinta da natureza dos indivíduos. Desse modo, uma crítica dos direitos do homem enquanto crítica de uma sociedade do egoísmo perde a visão clara da mutação do político que se operou para além das fronteiras do Estado de direito, noutros termos, por exemplo, de ver um ganho irretorquível na fórmula expressa em "todo homem é considerado inocente até que tenha sido declarado culpado" (LEFORT, 2011, p. 62-63 e 69-71). 
variável da impotência coletiva em tornar esses direitos uma medida de ação política concreta para além da estéril aposta penal.

Ademais, isso pode assinalar, nessa nova conjuntura, certa perda de força dos discursos políticos e sociais, absorvidos por premissas de punição que solapam a própria democracia. Em matéria penal, isso poderá não ser mais claro quanto ao tom monocórdio dos discursos de expansão do poder punitivo, assemelhando-se a leste ou a oeste. Quando eles se tornam crença ou se constituem puro ato de fé ideológico, a demagogia ganha, a passos largos, enorme espaço. Em razão de esses direitos terem a eficácia de preencher um vazio e poderem ser uma poderosa alavanca de transformação do futuro na falta de grande visão sobre o porvir, pensando em termos de política criminal, não raciocinar na defesa da urgente criminalização, no inchamento do Estado, na persecução penal e na punição severa é ser contra algo que deve ser feito imediatamente e cúmplice desse crime ${ }^{2}$ (GAUCHET, 2009).

No campo do mecanismo político propriamente dito, os direitos do homem como promessa de poder transformam-se em despossessão, sob o efeito da libertação das particularidades na qual se traduz. Particularidades canalizadas no poder de punir e que assinalam o completo esvaziamento

\footnotetext{
Surge uma espécie de novo maquiavelismo em primeiro plano nas democracias. Aquele do bem, "dedicado à celebração do homem e do direito, destinado ao ministério das justas causas e dos bons sentimentos, sem deixar de testemunhar sua humanidade, sua compaixão com as vítimas, sua preocupação com as mazelas do mundo." Eles remetem a uma separação entre o ideal e o real com que os governos agora se ocupam, correndo o risco de eles mesmos tornarem-se bodes expiatórios da resistência do real ao ideal. A passagem à ideologia consensual é uma fuga da era dos afrontamentos, um acordo feito em torno dos direitos que conduz a uma "despolitização dos meios" que beneficia os poderes que, nesta nova arte política, são seus meros executores. Por isso a precariedade de toda posição de poder no cerne de nossos regimes apaziguados. Uma expectativa, necessariamente frustrada, será o cerne de nossa política: "a democracia do consenso é uma democracia descontente." Nesse novo regime das convicções, apenas haverá lugar para a apreciação das intenções. Ao poder, como vetor do possível, bastará uma "política das intenções", da boa vontade generosa, indiferente ao desmentido do real. Não obstante, isso torna imunes os promotores, indiferente às consequências de suas disposições. Nesse ponto, sobretudo, o problema já haverá sido ressentido e não será mais atribuível a alguém em particular. Uma promessa de poder, de realização dos direitos do homem, acaba por tornar-se uma potência ininteligível, ou seja, o túmulo da política (GAUCHET, 2009, p. 348-350).
} 
de seus ideais sob o manto de uma suposta proteção emancipatória. Se eles podem afirmar as bases sobre as quais estamos reunidos, pouco oferecem, entretanto, a pensar a fabricação efetiva do ser-em-conjunto (GAUCHET, 2009), e por esse déficit acabam abrindo espaço para a reprodução impotente, permitida pelas recaídas no excesso de poder penal. Nosso encargo é saber se é isto que queremos: mergulhar na vertigem de uma degradação íntima da democracia atestada por essas tentações autodestrutivas.

Dessa forma, o ardor militante tende a desarticular qualquer aliança entre um pensamento de justiça daquele dos direitos da pessoa, passando, no momento, as reivindicações de justiça a se identificarem com as representações das vítimas. Em suma, o sistema protetivo dos direitos humanos acaba invertendo-se e contradizendo os próprios princípios ${ }^{3}$. Sob o manto da política penal, transformam-

3 Em matéria penal, sobre o assunto, Palazzo (1989, p. 103-115). A retórica atualizada da leitura sobre algum garantismo tem servido à semelhante prática de inversão discursiva que oferece arejadas (re)configurações da mesma nauseante senda (re)legitimadora do sistema penal, alheia ao enfraquecimento da própria democracia. Basta dizer que tal se resume desde acepções como "garantismo positivo", "garantismo penal integral" ou ainda "direito penal minimamente necessário" ou outras mais profundamente representadas por estruturas do neoconstitucionalismo em matéria penal ancoradas na "proibição por defeito ou por insuficiência de proteção" (Untermassverbot), que, estranhamente - devido à tamanha profundidade das análises hermenêuticas presentes -, aduzem a criminalização e o esgarçar do poder penal, perdendo de vista que qualquer controle desse tipo deve verificar se a proteção satisfaz as exigências de sua eficiência (cf. CANOTILHO, 2003 , p. 273) - o que, tratando-se de sistema penal, implica ignorar infindável manancial criminológico a respeito. Quanto à problemática do bem jurídico, cabem as palavras de Gregor Staechlin (2000, p.304): "el enfoque unilateral centrado en el pensamiento de la seguridad que se refleja en el postulado de la prohibición de infraprotección encuentra su parangón en el abuso del principio de protección de bienes jurídicos. La figura de la prohibición de infraprotección soslaya reflexiones legislativas necesarias. La función que se atribuye al Derecho penal desde el pensamiento unilateral de la seguridad no es compatible con el concepto liberal de Derecho penal que se ha esbozado. Parece urgente salir al paso del discurso de la política-criminal práctica para reclamar que se vuelva a plantear un tratamiento orientado a principios del sistema de Justicia criminal que tome en serio la dignidad y la libertad de la persona." Ademais, sobre a elucidativa abordagem do tema no panorama latino americano, ver Abad e Albarello (1999). De maneira mais aguda, a inversão ideológica dos discursos protetivos, seja na esfera penal mais localizada ou mesmo no âmbito ampliado dos direitos humanos, não é assunto novo, é de larga história. Quiçá se poderá dizer que a história dos direitos humanos é a própria história de sua violação, da mesma maneira que o poder punitivo, pois atribui um alvo ou objeto ao longo dos tempos a ser perseguido, sob o argumento do bem comum, da ordem e da defesa social - discurso contra o inimigo - ou qualquer outro termo localizado no grau zero de escrita (cf. BARTHES, 2006, p. 22). Enfim, ambos estão no mesmo espectro, não por contingência, mas porque assumem para si o mesmo "imperativo categórico", que será, ao fim e ao cabo, o mesmo de toda ação política: transformar a violação destes mesmos direitos protegidos em seu registro máximo. 
se em excelentes narcóticos que visam compensar os difusos males sociais. Mais diretamente, a inversão ideológica (HINKELAMMERT, 2000; HINKELAMMERT, 1987; HERRERA FLORES, 2009) dos direitos humanos se instaura diante da identificação de sua "política" com a imposição de poder e se transforma no suporte mais forte das políticas securitárias.

São as instituições de justiça, talvez mais do que qualquer outra, que se encontram confrontadas com os efeitos populistas. Quando, num primeiro momento político, a democracia reage, voluntariosa e programaticamente, de forma imediata ao crime, tomada pela parcialidade da emoção, o Ministério Público ou os órgãos de polícia vão à ajuda de uma sociedade ameaçada. Todavia, supõe-se o contrário no momento judicial, detido prudente e deliberadamente pelo seu trajeto processual penal. Algum culto ao rendimento é que poderá levar as instituições de justiça a não resistirem e tornarem-se vulneráveis às agitações de opinião. E o estatuto não elegível dos magistrados como funcionários públicos implica - correlata a essa maior exposição aos embates midiáticos e as críticas recebidas, pois é patente ter que manejar contra as eventuais maiorias, daí seu contrapoder de tutela de minorias donde retirará sua legitimidade (FERRAJOLI, 1995) - maior responsabilidade atrelada aos poderes daí advindos: "un juge enrôlé dans une croisade contre le crime n'est plus à sa place de tiers impartial; il prende le rôle d'un "saint belliqueux» voué à une mission sacrée, au risque de briser les principes qui gouvernent sa fonction" (SALAS, 2010, p. 234).

\section{A ostensão penal}

Diante do que foi exposto, somos capazes de perceber que há uma força pronunciada que pouco se deve a qualquer foco externo senão à disseminação de uma estratégia viral que corrói o corpo social e a própria democracia. Hoje, poderíamos superficialmente falar do hiperterrorismo ou de qualquer outra formação de um eventual conceito 
de inimigo (cf., em sentido profundo, ZAFFARONI, 2007, p. 65-694) sem passar pelo que realmente importa. Se quisermos acompanhar Derrida (2004), há uma espécie de terror interno que produz uma "autoimunização" na democracia - pois se sabe que o pior e mais eficaz terrorismo, ainda que pareça externo ou internacional, é aquele que instala uma ameaça interior e lembra que o inimigo está também alojado dentro do sistema, ou seja, destrói suas defesas imunitárias, subverte sua linguagem e fragiliza suas instituições. $O$ acontecimento do 11 de setembro, como caso paradigmático, apenas fez emergir a autodestruição dos mecanismos de defesa democráticos de acordo com um impacto mental de um mal que conduz a uma contraviolência a sua imagem. A tortura em nome da democracia aliada da cultura da guerra (tal como advoga POSNER, 2006, p. 77-104) e a retórica punitiva em nome das vítimas concedem um potente elã ao discurso político.

Uma democracia que não entende mais a disposição global de si que constitui a metade de seu ser, que não é mais atenta à coexistência de suas partes tornada um fim nela mesma, é uma democracia que não compreende mais, não mais, as bases sobre as quais ela repousa e os instrumentos dos quais necessita. Ela não sabe mais conferir um estatuto aos limites da comunidade histórica graças aos quais ela é capaz de agir sobre si mesma, ela não tem mais o sentido do aparelho de autoridade que lhe permite aplicar-se sobre si mesma. (GAUCHET, 2009, p. 363)

Há uma lei implacável que regula todo esse processo autoimunitário, ou seja, uma lógica que faz com que a democracia trabalhe por si, quase de forma suicida, exatamente para imunizar a própria proteção.

4 Quanto mais difuso o conceito, mais ele se presta a uma apropriação oportunista, assim nos alerta Derrida (2004). E será o poder dominante aquele que consegue impor e legitimar - na verdade, até legalizar (pois sempre se trata de uma questão de lei) -, em um palco nacional ou mundial, a terminologia e a interpretação que mais lhe convém em uma determinada situação. 
Inicialmente, ela deve ser desencadeada por um acontecimento ${ }^{5}$ que, como tal, carrega em si algo de inapropriável, certa incompreensibilidade. Essa transgressão de novo tipo acarreta um trauma, uma ferida não apenas marcada na memória. Nesse ponto, é salutar repensar essa temporalização tão hábil a ser veiculada no populismo punitivo. A ideia no $11 \mathrm{~S}$ como "acontecimento maior" (mas o esquema se mantém rijo para nossa análise) nos dá condições de perceber claramente que não é o presente ou o passado que determinam essa inapropriabilidade, e sim o porvir. Falando de traumatismo, ele é produzido pela ameaça de que o pior está por vir; o medo do que já foi não será maior do que o pavor e a iminência de uma agressão futura. Daí o "inapresentável futuro" reger uma racionalidade de permanente estado de prontidão e antecipações de todas as espécies de meios repressivos, numa espécie de estado de defesa contínuo que inventa e alimenta a própria monstruosidade que alega superar:

O que nunca se deixará esquecer é, assim, o efeito perverso da auto-imunidade em si. Pois sabemos agora que a repressão, tanto no seu sentido psicanalítico quanto no político - seja através da polícia, dos militares ou da economia -, acaba produzindo, reproduzindo e regenerando justamente a coisa que pretendeu desarmar. (DERRIDA, 2004, p. 106-109)

Já estamos, pois, mergulhamos no círculo vicioso da repressão. Com um clima de guerra universal contra o crime, campeia a dissolução da política pelas emoções coletivas. Mais viável a aclamação que a tudo torna homogêneo. O apelo do poder é enviado a um povo imaginário muito mais adequado a uma ideologia que presumivelmente coloca a pluralidade do povo real como ingovernável. O lugar vazio do poder, uma vez suposto por Lefort (2011) como princípio da democracia, que deve representar a

5 Rumo a um sentido de expropriação segundo Derrida (2004, p. 100 e 104): "o acontecimento é o que surge, e, ao surgir, surge para me surpreender, para surpreender e suspender a compreensão: o acontecimento é antes de mais nada tudo aquilo que eu não compreendo. Consiste no aquilo, em aquilo que eu não compreendo: aquilo que eu não compreendo: minha incompreensão. [...] Daí a inapropriabilidade, a imprevisibilidade, a absoluta surpresa, a incompreensão, o riso de mal-entendido, a novidade não antecipável, a pura singularidade, a ausência de horizonte". 
perpétua abstenção democrática em aceitar fundamentos últimos que disponham sobre certezas derradeiras, é facilmente preenchido, hoje, por qualquer demanda punitiva.

Agamben (2009) lembra que, em 1928, Carl Schmitt procurou estabelecer o significado constitutivo das aclamações no direito público, quando tratava, em sua Teoria da Constituição, da relação do Povo com a Constituição Democrática. Schmitt vincula de modo indissolúvel a aclamação à democracia e à esfera pública (povo). Para ele, a opinião pública é a forma moderna de aclamação e é nela que se encontra a essência de seu significado político. Mesmo não ignorando os perigos de certas forças sociais dirigirem a opinião pública e a vontade do povo, isso seria problema menor, desde que assegurada a capacidade que considerava decisiva para a existência política de um povo: a refundação categórica do político desde a decisão que distingue entre amigo e inimigo - "Freund und Feind" (SCHMITT, 2001).

Para Agamben (2009), é a aclamação que parece pertencer à tradição do autoritarismo, sobretudo desde a sua esfera da glória (preocupação central do autor ${ }^{6}$ ), que, nas democracias modernas, foi deslocada para o âmbito da opinião pública. O que está em questão, em síntese, é a multiplicação e a disseminação da função da glória (com toda as matizes da liturgia e dos cerimoniais repaginadas), agora concentrada na mídia. Ganha também sentido, pois, aquilo que já comentamos a respeito de alguma democracia de consenso. De uma

$6 \quad$ O poder, como governo político dos homens, rastro das pesquisas de Foucault, também é o interesse de Agamben (2009). Sobre a genealogia da governabilidade, tem força situar o governo em seu locus teológico na oikonomia trinitária. Esse dispositivo é concebido como laboratório privilegiado para observar a máquina governamental. Mas é sobre a correlação entre oikonomia e glória que ele investe, ou seja, faz-se a pergunta: por que o poder precisa da glória, e qual a relação entre glória e economia? Assim, entre o poder como governo e gestão eficaz e o poder como realeza cerimonial e litúrgica, abre-se um campo vasto para identificar a Glória como arcano central do poder e interrogar sobre o nexo indissolúvel que a vincula ao governo e à oikonomia. Em poucas palavras, estamos diante do aspecto aclamativo e doxológico do poder, identificável hoje nos meios de comunicação e nas democracias contemporâneas em seu government by consent (governo por consentimento) ou consensus democracy (democracia do consenso). Isso, de alguma forma, permite captar o vazio central da máquina governamental, aproximando o pensamento de Lefort, o símbolo mais carregado de poder, ou seja, o trono vazio que é o símbolo mesmo da Glória (cf. AGAMBEN, 2009, p. 187-284). 
parte, tensionando ainda mais a posição acerca da transformação das instituições democráticas, ver-se-á, segundo o autor, que os teóricos do "povo-comunicação" - tal como Habermas (1984), que advoga uma soberania popular totalmente emancipada de um "sujeito-povo substancial", mas inteiramente resolvida nos processos comunicativos privados que, segundo sua ideia de esfera pública, regulam o fluxo da formação política da opinião e da vontade - acabam por entregar o poder político nas mãos dos especialistas e da mídia. Cai-se numa espécie de glória midiática e objetiva da comunicação social.

A riqueza da letra de Agamben (2009, p. 283) está em demonstrar que o government by consent e a comunicação social remetem a aclamações:

il consenso può essere definito senza difficoltà, parafrasando la tesi schmittiana sull'opinione pubblica, come «la forma moderna dell'acclamazione» (poco importa che I'acclamazione sai espressa da una moltitudine fisicamente presente, come in Schmitt, o dal flusso delle procedure comunicative, come in Habermas).

A "sociedade do espetáculo", de Debord (1997), assume, pois, novo significado e pujança. A glória acaba sendo a substância da qual a politicidade vai retirar seu critério e onde o povo real ou comunicacional das democracias consensuais contemporâneas acaba por repousar. O que nos alerta para os perigos do consenso em democracia, com destaque para as aclamações midiáticas por punição.

A temática populista traz consigo o inquietante progresso de uma democracia cada vez mais desafeta a um desacordo de opiniões. A tirania da urgência em relação ao crime nos leva a tentar deslocar o panorama do populismo punitivo, para inquirirmos, de soslaio, a "razão" do desejo punitivo ou aclamação populista pela punição, que pode, de alguma maneira, mover essas práticas generalizadamente.

Para tanto, com a ajuda de Laclau (2010), podemos visualizar o populismo como um modo de construir o político, além de ser um fenômeno inscrito em todo espaço comunitário. Mesmo que nossa 
leitura possa ser, em algum instante, menos complacente do que a do professor argentino quanto às potências benéficas do povo, nossa preocupação objetiva surpreender o populismo, uma lógica social que atravessa uma série de fenômenos, especialmente nas configurações próprias das demandas punitivas.

A lógica do populismo e a forma própria de formação das identidades coletivas passam pela premissa de se apoiar no estudo de unidades menores, não os grupos, mas as demandas. Por isso outorgar centralidade ao afeto (cf. FREUD, 2005, p. 2.563-2.610) como componente constitutivo de qualquer laço social. Um enfoque alternativo do populismo, assim, pode deixar a conhecê-lo como uma constante da ação política. E a sua vagueza e imprecisão conceitual não podem ser perdidas numa mera operação política tosca. Pelo contrário, na indeterminação do populismo, há um ato performativo dotado de racionalidade própria, porque é essa mesma simplificação que permite a associação de demandas heterogêneas. No tocante a esses jogos de diferenças que ganham centralidade hegemônica, a ilustração das diversas iniciativas penalizantes, nas mais diversas áreas, inclusive não raro com interesses de fundo contrapostos, são catapultadas a significantes vazios (são os ditos bens jurídicos) que atam firmemente a cadeia do discurso punitivo. Se o populismo é vago e indeterminado nesse ponto, o é exatamente para ser dotado, ao fim, de coesão interna ${ }^{7}$ (LACLAU, 2010; LACLAU; MOUFFE, 1987).

7 Três categorias tornam-se fundamentais aqui entender. Primeiro o discurso, visto mais amplamente como terreno primário da constituição da objetividade como tal, ou seja, um complexo de elementos nas quais as relações têm um papel decisivo, sendo elas de dois tipos: combinação e substituição, exatamente retiradas dos tropos acerca da metonímia e da metáfora lacaniana. Mas o que importa frisar são os jogos de diferenças estabelecidos, não se dando privilégio a nenhum elemento a priori, adquirindo centralidade de acordo com as relações forjadas. Em segundo, há os significantes vazios e a hegemonia. Em se tratando de identidades diferenciais, o todo dentro do qual elas se constituem estará contido em cada ato individual de significação. Segundo o autor, isto implica ter em conta que uma totalidade apenas pode constituir-se por exclusão, o que faz com que todas as outras diferenças sejam equivalentes entre si, em seu rechaço comum a identidade excluída. A equivalência, agora, subverte a diferença, dentro de uma identidade construída a partir da tensão entre uma lógica da diferença e uma lógica da equivalência. A totalidade aqui é vista como elemento impossível, mas necessário, para precisamente haver a possibilidade de uma diferença, sem deixar de ser particular, assumir a representação 
Nessa vertente, as demandas sociais, quando insatisfeitas por uma incapacidade institucional de resolvê-las diferencialmente, acabam por potencializar certa carga equivalencial, diríamos "simplificadora", entre elas. Isso acaba formando uma cadeia, uma unificação das demandas (LACLAU, 2010), no caso em análise, facilmente em torno da questão punitiva. Sendo a construção do povo o ato político por excelência, a política tout court - em que é essencial a formação de fronteiras antagônicas dentro do social convocando novos sujeitos e a produção de significantes vazios com o fim de unificar em cadeias equivalenciais um conjunto de demandas heterogêneas - e o rasgo definidor do populismo, ao que parece também de qualquer intervenção política, cabe exercitar a paciência crítica de acompanhar para onde podem flutuar esses significantes.

Sendo mais direto, pode-se interrogar: e se para a constituição do povo, desse significante vazio, certa contingência conduzir para a simplificação penal? Não será o próprio dispositivo da Constituição, e mais amplamente o valor da Democracia, dentro de um cenário de ostensão punitiva conduzida por um jogo de diferencialidades, os significantes vazios prontos a definirem uma política penal repressiva? Assenta-se que tal é a centralidade do poder punitivo no atual esquema democrático constitucional que não é temerário ver o palco das relações de força, da articulação histórica contingente (na sucessão descontínua de formações hegemônicas), aportar cada vez mais identidades políticas prontas a demandarem a hegemonia do discurso punitivo. Em suma, sobre as tendências populistas é que o acento se põe e as respostas se colocam naturalmente.

de uma totalidade incomensurável: "Esta operación por la que una particularidad asume una significación universal inconmensurable consigo misma es lo que denominamos hegemonía. Y dado que esta totalidad o universalidad encarnada es, como hemos visto, un objeto imposible, la identidad hegemónica pasa a ser algo da orden del significante vacío, transformando a su propia particularidad en el cuerpo que encarna una totalidad inalcanzable." (LACLAU, 2010, p. 95). O terceiro elemento condiz com a retórica, onde um termo literal é substituído por um termo figurativo. A nomeação do inominável é exatamente a condição de ser da própria linguagem e, portanto, da operação hegemônica, passando a ser, assim, o denominador comum para a construção do povo a catacrese (figura de linguagem da retórica clássica que remete ao uso de um termo que não descreve com exatidão o que quer expressar, mas é posto por não haver outra palavra apropriada). 


\section{Traços finais: nas pegadas do desejo de liberdade}

A disposição contemporânea da ostensão penal, como vimos, tem seu fortalecimento eficiente nos anseios punitivos de diversos calibres. A nova economia do castigo inova nas zonas centrífugas da segurança, integradas cada vez mais aos mecanismos jurídico-disciplinares. Se as estratégias securitárias de severidade, a todo custo catapultadas pelo medo, aglomeram-se às pretéritas práticas disciplinares e de soberania, a normalização do seu modelo ótimo - além de agenciada coletivamente inclusive pelos atores político-jurídicos responsáveis em tese pela sua limitação - traz em seu epicentro uma gama de práticas do mais amplo leque ideológico, já que uma vontade de punir, representada pelo populismo punitivo e forçada ao extremo, torna-se claramente uma componente forte da vida democrática no horizonte constitucional. Uma demagógica sociedade de emoção, envolvida na vertigem da ostensão penal, vem funcionando desde um aclamado e preciso consenso repressivo. O populismo, enfim, casa-se perfeitamente com a punição, na medida em que, sendo vago e indeterminado, capacita a coesão de diferentes demandas heterogêneas. As demandas localizadas nos diversos grupos de interesses acabam por (su)portar tal desejo e trabalham, pois, a reforçar os afetos performaticamente em torno da cadeia do discurso punitivo.

Nessas sendas é que deve pairar alguma tentativa de recuperar o desejo de liberdade, para não deixá-lo soterrar frente às demandas punitivas, tarefa nunca das mais fáceis. Se nas sociedades modernas democráticas o maior perigo, como escreveu Christie (1993, p. 24), não é o delito em si, mas que a luta contra ele conduza aos piores totalitarismos, por conseguinte, a resignação e o pessimismo não poderão ter acento firme, muito menos em tempos sombrios. Não ceder no discurso de resistência, próprio também ao Direito Penal, escapando do Zeitgeist, que tantas vezes ensaiou-se como desculpa às piores atrocidades cometidas em tempos sombrios, parece a prova a ser cumprida reiteradamente frente às barreiras derrubadas pelo Estado de Polícia. 


\section{Referências}

ABAD, Iván Orozco; ALBARELLO, Juan Gabriel Gómez. Los peligros del nuevo constitucionalismo en materia criminal. Santa Fé de Bogotá: Temis, 1999.

AGAMBEN, Giorgio. II regno e la gloria: per una genealogia teologica dell'economia e del governo. Homo sacer, II, 2. Torino: Bollati Boringhieri, 2009.

BARTHES, Roland. O grau zero de escrita. Tradução de Maria Margarida Barbahona. Lisboa: Edições 70, 2006.

CANOTILHO, J. J. Gomes. Direito constitucional e teoria da constituição. 7. ed. Coimbra: Almedina, 2003.

CHRISTIE, Nils. La industria del control del delito ¿La nueva forma de holocausto? Prólogo de Eugenio Raúl Zaffaroni. Buenos Aires: Editores del Puerto, 1993.

DEBORD, Guy. A sociedade do espetáculo: comentários sobre a sociedade do espetáculo. Tradução de Estela dos Santos Abreu. Rio de Janeiro: Contraponto, 1997.

DERRIDA, Jacques. Auto-imunidade: suicídios reais e simbólicos: um diálogo com Jacques Derrida. In: BORRADORI, Giovanna (Org.). Filosofia em tempo de terror: diálogos com Jürgen Habermas e Jacques Derrida. Tradução Roberto Muggiati. Rio de Janeiro: Jorge Zahar, 2004. p. 141-175.

FERRAJOLI, Luigi. Derecho y razón: Teoría del garantismo penal. Traducción de Perfecto Andrés Ibáñez et al. Madrid: Trota, 1995.

GARLAND, David. La cultura del control: crimen y orden social en la sociedad contemporánea. Traducción de Máximo Sozzo. Barcelona: Gedisa, 2005.

GAUCHET, Marcel. A democracia contra ela mesma. Tradução de Sílvia Batista de Paula. São Paulo: Radical Livros, 2009. 
HABERMAS, Jürgen. Mudança estrutural da esfera pública: investigações quanto a uma categoria da sociedade burguesa. Tradução de Flávio R. Kothe. Rio de Janeiro: Tempo Brasileiro, 1984.

HERRERA FLORES, Joaquin. Teoria crítica dos direitos humanos: os direitos humanos como produtos culturais. Tradução de Luciana Caplan et al. Rio de Janeiro: Lumen Juris, 2009.

HINKELAMMERT, Franz J. La inversión de los derechos humanos: El caso de John Locke. In: HERRERA FLORES, Joaquín (ed.). El vuelo de anteo: derechos humanos y crítica de la razón liberal. Bilbao: Desclée de Brouwer, 2000. p. 79-113.

HINKELAMMERT, Franz. Democracia \& totalitarismo. Santiago: Amerinda, 1987.

LACLAU, Ernesto. La razón populista. Buenos Aires: Fondo de Cultura Económica, 2010.

LACLAU, Ernesto; MOUFFE, Chantal. Hegemonía y estrategia socialista: Hacia una radicalización de la democracia. Buenos Aires: Fondo de Cultura Económica, 1987.

LEFORT, Claude. A invenção democrática: os limites da dominação totalitária. 3. ed. rev. atual.; inclui textos inéditos. Tradução de Isabel Loureiro e Maria Leonor Loureiro. Apresentação de Marilena Chauí. Belo Horizonte: Autêntica, 2011. v. III. (Coleção Invenções Democráticas).

PACKER, Herbert L. Limits of the criminal sanction. Stanford: Stanford University Press, 1968.

PALAZZO, Francesco C. Valores constitucionais e direito penal. Tradução de Gérson Pereira dos Santos. Porto Alegre: Sérgio Antonio Fabris, 1989.

PIRES, Alvaro Penna. La ligne Maginot en droit criminel: la protection contre le crime versus la protection contre le prince. Revue de droit pénal et de criminology, Bruxelles, ano 81, n. 2, p. 145-170, févr. 2001.

POSNER, Richard A. Not a suicide pact: the constitution in a time of national emergency. Oxford: Oxford University Press, 2006. 
SALAS, Denis. La volunté de punir: essai sur le populisme pénal. Paris: Arthème Fayard/Pluriel, 2010.

SCHMITT, Carl. Teoría de la constitución. Versión española de Francisco Ayala. Madrid: Alianza, 2001.

STAECHELIN, Gregor. ¿Es compatible la «Prohibición de Infraprotección» con una Concepción Liberal del Derecho Penal? In: INSTITUTO DE CIENCIAS CRIMINALES DE FRANKFURT (Ed.). La insostenible situación del derecho penal: área de Derecho Penal de la Universidad Pompeu Fabra (Ed. Española). Granada: Colmares, 2000. p. 289-304.

ZAFFARONI, Eugenio Raúl. O inimigo no direito penal. Tradução de Sérgio Lamarão. Rio de Janeiro: ICC/Revan, 2007.

Data de recebimento: $15 / 03 / 12$

Data de aprovação: 22/11/12 